\title{
En lo alto para siempre: la presencia y la recepción del cuerpo como puesta en abismo
}

\section{( Carla Daniela Abelando}

Facultad de Filosofía y Letras (UBA)/carla.abelando@gmail.com

Fecha de recepción: 30/o8/2018. Fecha de aceptación: 26/og/2018.

\begin{abstract}
Resumen
A través del cuerpo -soporte material de la actuación- y sus recursos expresivos, se encarna la condición efímera de la existencia, tanto del hecho teatral como de la vida misma, y la constante posibilidad latente de saltar al vacío, que es, al mismo tiempo, la característica indispensable de todo acontecimiento teatral, poseedor de la incertidumbre e imprevisibilidad inherentes a toda experiencia viva y mutable. Dicha temática se hace explícita en la puesta en escena En lo alto para siempre (2018) de Camila Fabbri y Eugenia Pérez Tomas, la cual interpela e incomoda la mirada del espectador, debido a la presencia de lo ausente (de la muerte) mediante acciones corporales, repetitivas y enérgicas, en un juego especular que refleja la propia naturaleza efímera de los espectadores, y que, cual puesta en abismo de su desarrollo temático en el texto dramático, tiene su mayor pregnancia en la corporalidad y materialidad puestas en juego. Para llevar a cabo el presente análisis, se abordan diversos autores que plantean los nuevos paradigmas teatrales de los últimos años, en los cuales el eje vertebrador es el encuentro de los cuerpos presentes.
\end{abstract}

\section{Presence and Reception of the Body as Mise en abyme in En lo alto para siempre}

\begin{abstract}
Abstrract
The body -material basis of acting- and its expressive resources represent the ephemeral existence, both of theatre and of life itself, and the constant and latent posibility of jumping into the void, which is, at the same time, the essential characteristic of every theatrical event, unpredictable and uncertain, such as every living and mutable experience. This topic is explicit in the staging of En lo alto para siempre (2018) by Camila Fabbri and Eugenia Pérez Tomas, because it inconveniences the spectators due to the presence of the absent (death) through physical, repetitive and intense actions, which seem to be the reflection of the actual
\end{abstract}

Palabras clave

Cuerpo presencia acción abismo efímero

Keywords Body Presence Action Mise en Abyme Ephemeral 
ephemeral condition of the spectators and the mise en abyme of the dramatic text that develops the same issue. To analyze this, the present article considers several authors that examine the latest theatrical paradigms, in which the encounter of the present bodies is the backbone.

Contra viento y marea, el hecho teatral es uno de los pocos acontecimientos artísticos que desafía los nuevos paradigmas establecidos en una era signada por la comunicación hipermediatizada, fragmentaria, inmediata y estallada de imágenes y reproducciones. Dicha resistencia se mantiene firme gracias a la condición sine qua non del acontecimiento teatral: el convivio ${ }^{1}$ imprescindible entre el cuerpo del actor y el espectador, en un tiempo y espacio compartidos, sin mediaciones ni mediatizaciones posibles: "un lapso de vida en común que actores y espectadores pasan y agotan juntos" (Lehmann, 2013: 28). El cuerpo -soporte material concreto, vivo- conlleva en sí mismo las marcas del tiempo que, al ser expectado como "cuerpo objeto que se expone para ser contemplado por otro" (Trastoy y Zayas de Lima, 2006: 45) en escena, remite a lo efímero, mutable e impredecible de la condición humana y de la vida misma. De esta manera, a través de los cuerpos actuantes se manifiestan la incertidumbre y la imprevisibilidad -tanto del hecho teatral como de la vida- con mucha mayor pregnancia y determinación que en el resto de los lenguajes escénicos. La actuación ya no se concibe como representación de "un cosmos ficticio cerrado, un universo diegético (...) de una realidad aislada y enmarcada, en la cual dominan sus propias leyes (...)" (Lehmann, 2013: 171 $)^{2}$, sino como la encarnación de lo abismal, del riesgo que implica su entrega al "aquí y ahora", una constante posibilidad latente de saltar al vacío, de arrojarse a lo desconocido, característica inherente del hecho vivo que no tiene posibilidad de ser controlado. Este acto de arrojo pone en jaque la mirada del espectador que, lejos de cumplir un rol pasivo durante el hecho teatral, se vuelve no solo testigo de la incierta posibilidad de caída, sino también copartícipe de la adrenalina y la intensidad emocional de los cuerpos en escena, que interpelan, e incluso incomodan, al espectador, al formar parte de un juego especular en el que éste se ve reflejado como portador de un cuerpo efímero y finito como aquel que especta.

En la puesta en escena de En lo alto para siempre -estrenada en el Teatro Nacional Cervantes en el 2018-, puede observarse cómo se ponen en juego las mencionadas características a través de los cuerpos de las actrices y actores, y de sus posibilidades expresivas. La puesta genera niveles de tensión entre los cuerpos en escena y las miradas que los contemplan, muestra de forma explícita la constante puesta en riesgo que implica la actuación, concientizando a los espectadores acerca de la vivencialidad hic et nunc -no ilusoria, no reproducible-, y del salto al vacío que significa entregarse a la misma.

El eje temático en En lo alto para siempre es la muerte de un hijo, un suicidio provocado por un salto al vacío, una caída mortal. Sin embargo, el texto espectacular y determinados recursos actorales son los que constituyen la más profunda reflexión de dicha temática: la materialización de la condición transitoria e inefable de la vida, de los cuerpos y, por ende, del hecho teatral, como pasaje hacia la muerte, como instancias pasajeras, voraces y fugaces. Asimismo podría hablarse de -aplicando conceptos de Lehmann (2013: 29)-: una auto-reflexión de la práctica escénica y actoral en sí misma, una auto-tematización (disfrazada de argumento). A pesar de que el texto dramático -dada su continua presencia, sus juegos retóricos, sus repeticiones, su extensión, entre otras caraterísticas- aparenta ocupar un lugar privilegiado, éste parece funcionar a modo de trampolín para las operaciones físicas y actorales que encarnan de manera determinante aquello que las palabras relatan, en otras palabras, las acciones físicas son la puesta en abismo de la temática y constituyen el elemento más pregnante
1. n palabras de Dubatti, el "acontecimiento en el que artistas, técnicos y espectadores se reúnen en cuerpo presente para expectar " (2016: 9).

2. Según Lehmann, ésta es la premisa central de la idea tradicional del teatro, correspondiente a la categoría de drama moderno. 
del hecho teatral. Así, el texto lingüístico queda socavado en lo que Lehmann llama performance text: "A través de él el teatro deviene presencia más que representación, experiencia compartida más que comunicada, proceso más que resultado, manifestación más que significación, energía más que información..." (2013: 149), es decir, el texto de la escenificación, cuyo conjunto de elementos constitutivos -sistemas de signos interrelacionados- está determinado fundamentalmente por el cuerpo, el cual "asume la pluralidad de los códigos que operan en la puesta en escena, organizando y marcando el sentido direccional del espacio, sosteniendo y condicionando la <<polifonía informacional >>" (Trastoy y Zayas de Lima, 2006: 45). A continuación, se ejemplificará con el material de la puesta en escena, de qué manera se ponen en juego dichas cuestiones.

En En lo alto para siempre, escrita y dirigida por Camila Fabbri y Eugenia Pérez Tomas, la puesta gira en torno a Virginia, una madre -interpretada por María Onetto- que vivencia el suicidio de su hijo y queda estancada en esa situación. El estancamiento es literal: no puede bajar de la terraza de la que su hijo, Pablo, se arrojó fatalmente, y la caída también lo es: el público se vuelve testigo, cómplice silencioso, de su salto en escena una y otra vez. Tanto al inicio como al final del texto espectacular, sumadas a unas cuantas veces más durante su desarrollo, Pablo salta de la terraza, configurando una especie de escena recurrente en la memoria de Virginia quien, junto a los espectadores testigos de su recuerdo, contempla la caída que quiebra su vida sin vuelta atrás. El resto de los personajes -Lidia, su hija embarazada, y Emilio, un plomero que en lugar de realizar su supuesto trabajo termina implicado emocional, mental y físicamente en esta situación- no perciben al muchacho que cada vez que salta al vacío va componiendo un leitmotiv de destrezas físicas e incesante dolor. Tanto la mirada de Virginia como la de los espectadores son sometidas a presenciar ese instante de pasaje ritual a otro estado, aquella voluntad irracional de arrojarse al abismo, que provoca una vertiginosa incomodidad en la platea, en relación al cuerpo presente del actor y a su integridad física, pero también en relación al plano representacional de la acción que remite incesantemente a la proximidad y la abrupta imprevisibilidad de la muerte. Esta situación recurrente y pesadillesca es recibida por Virginia siempre con el mismo gesto y el mismo sonido, una expresión ahogada de dolor sin remedio, como una puñalada adentro que abre una herida imposible de cerrar y que comparte a través de este gesto reiterativo. Dicho "proceso ritual" (De Marinis, 1996: 175) encarnado en los saltos, opera en diversos niveles semánticos al mismo tiempo: por un lado, convoca en el público y en el personaje de la madre la concientización de lo finito de la existencia humana, su intrínseca condición efímera y, más aún, la capacidad de cada persona en sí misma de poner fin al propio cuerpo, el vértigo que provoca tener ese poder y libertad en las propias manos (hecho que también se muestra durante la puesta en escena mediante diversas situaciones en las que los cuerpos de los tres personajes coquetean, a veces con la acción y otras veces con el discurso verbal, con la posibilidad de tirarse de la terraza, con la muerte que ronda, provocando nuevamente la incertidumbre en el espectador); y, por otro lado, funciona como materialización de lo abismal del propio hecho teatral, una especie de auto-reflexión que, al confrontar el proceso ritual -la caída repetitiva, el signo que retorna sin cesar, el fin inminente- con (y dentro de) el proceso teatral, funciona como "verdadero rito de pasaje, de muerte y de renacimiento, para el actor" (1996: 175), quien, en este caso, literalmente muere (salta) y renace (se levanta para luego volver a saltar) una y otra vez, en un rito que se repite, en la ejecución y en la expectación, en cada función. Asimismo, puede pensarse en el concepto de "liminalidad", implícito en todo fenómeno teatral en el que conviven la materialidad real de los cuerpos con su capacidad poiética, es decir, la constante "tensión de campos ontológicos diversos en el acontecimiento teatral: arte / vida; ficción / no-ficción; cuerpo natural / cuerpo poético; presencia / ausencia (...)" (Dubatti, 2016: 14), que en En lo alto para siempre se vuelve explícito en el cuerpo de Pablo que se expone a la caída, a la destreza física, 


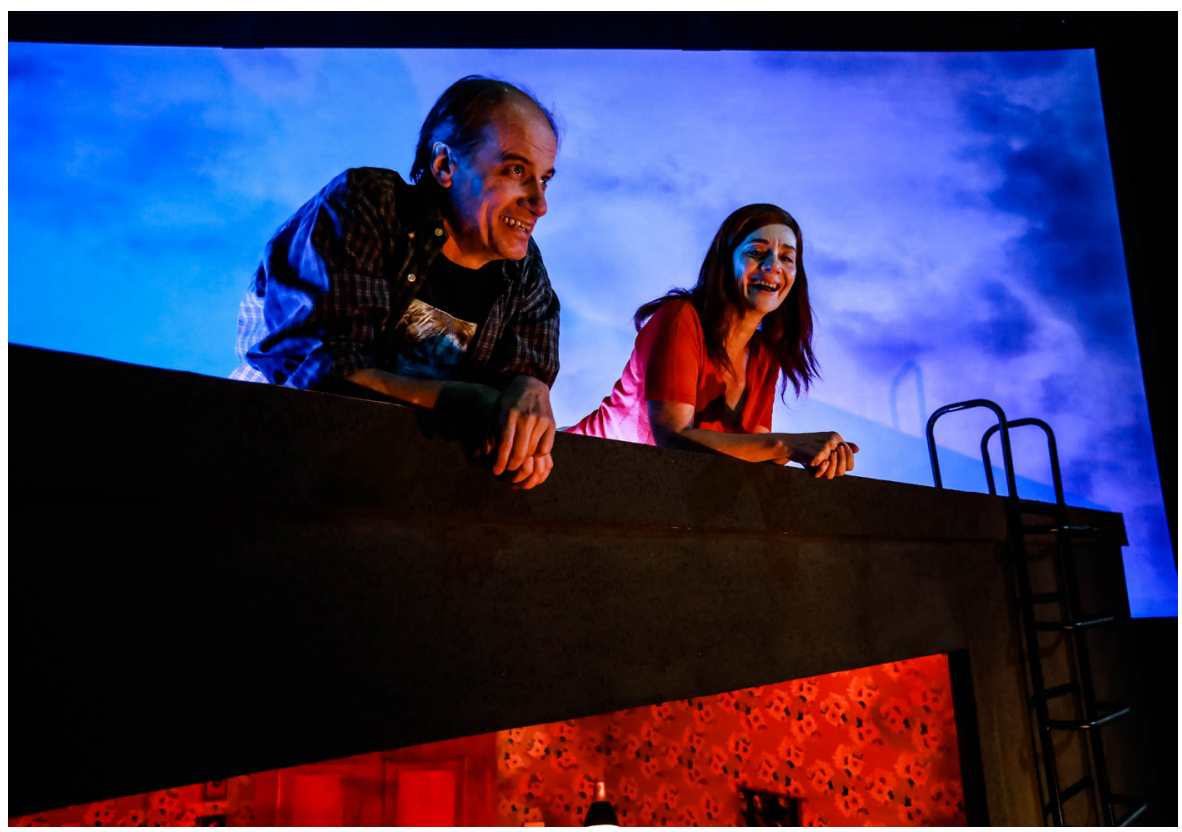

a la acción concreta con el riesgo real que impacta en la recepción, y que, a su vez, representa ese instante imborrable en la memoria de su madre, funcionando así como "estatuto híbrido, limítrofe precisamente (en el sentido de 'en el umbral' entre realidad y ficción), que sería constitutivo del espectáculo teatral (...)" (De Marinis, 1996: 175).

Por otra parte, el tono de las actuaciones en la puesta puede resultar cercano al naturalismo, con vestuarios, objetos escenográficos, vínculos actanciales y "diálogos de intervenciones cortas y escenas que se suceden con rapidez, una especie de realismo urbano que trata igualmente de temas cotidianos" (Cornago, 2004: 603), pero simultáneamente se encuentra plagado de sutilezas, pequeños gestos, palabras y detalles, que remiten levemente a una estética absurdista. Por ejemplo, esta característica puede observarse en los relatos de la madre acerca del suicidio de su hijo, que narra ella a continuación de los saltos: cada vez que vuelve sobre el mismo relato del hecho traumático alterna la historia de su hijo con comerciales que estaba viendo por televisión sobre productos de limpieza, generando de esta manera un tiempo fragmentario en el relato, una alteridad teñida de absurdo, mientras su actuación está constantemente cargada de una gran intensidad emocional, de un estado afectado de principio a fin (propio del entrenamiento que propone Ricardo Bartís, director y pedagogo teatral con el que la actriz realizó su formación actoral): "un teatro de estados que <<busca fragmentar la historia, explorar las intensidades del personaje a través del cuerpo del actor que es traspasado por las situaciones y por múltiples discursos, por muchas presencias y resonancias" (en Trastoy y Zayas de Lima, 2006: 50).

De esta manera, se advierte en la puesta en escena lo que Fernández Peláez denomina "auras de la presencia", es decir, las propiedades auráticas, enérgeticas, que emanan de la presencia de los cuerpos-mentes de los actuantes, de la manifestación de lo que realmente contiene: los impulsos, pensamientos, intenciones y afectaciones de las actrices y actores, su presentación (superadora de la re-presentación). Se tiende así a
En lo alto para siempre - Créditos de imagen: Gustavo Gorrini Gentileza: Prensa TNA - TC. una exposición del estado de conciencia al que voluntariamente se somete el actuante, convirtiéndolo en persona que en tiempo presente permite al espectador conformar emocionalmente la escena, no ya desde una referencia, sino desde la tangible comprobación de la existencia del ser del actuante en escena. (Fernández Peláez, 2014: 158). 


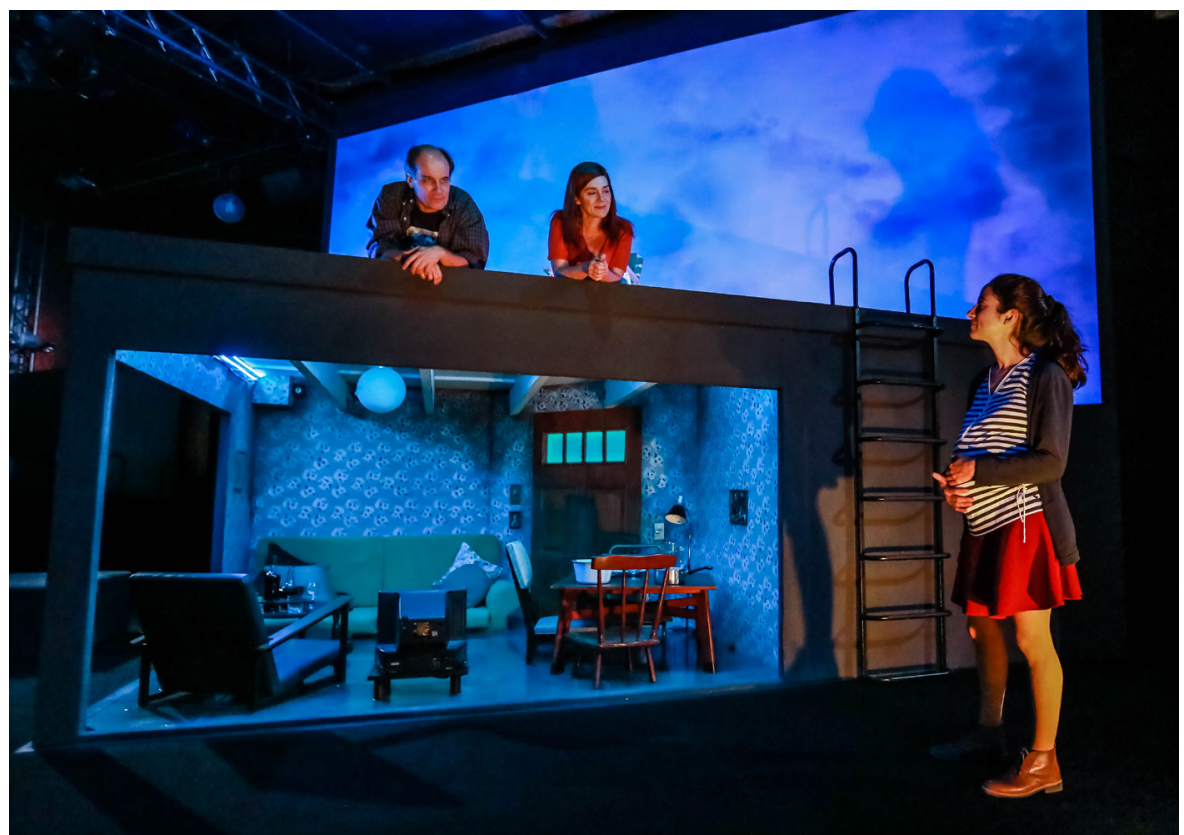

Las acciones de las actrices y actores están sumidas en una "exposición directa y vivencial" (2014: 159) de una realidad física y emocional auténtica (no imitativa, no reproductiva) en las que se hace visible la presencia e interpelan al espectador que se encuentra con ellas al ser evocativas y provocativas de sus propias emociones, reflexiones y corporalidades.

Si bien en En lo alto para siempre predomina la quietud y el escaso desplazamiento de los cuerpos en escena (con excepción del personaje del hijo que brinca ágilmente cada vez que hace su aparición), la afirmación del "cuerpo como primigenio artífice del relato" (2004: 159) es confirmada indiscutiblemente en las dos escenas en que danzan. En primer lugar, en mitad del desarrollo de la puesta en escena, suena una canción de Alanis Morissette, la cual uno a uno los personajes comienzan a danzar. Se combinan en esta escena dos elementos constitutivos del hijo, esa "ausencia presente" o "presencia ausente" que se cuela en cada intersticio de la puesta: la música noventosa que él escuchaba y la danza ritual que a él había conmovido. Previo a este baile, se hace alusión a una danza ritual indígena que Pablo había presenciado en Potosí y que había representado uno de los pocos momentos de felicidad en su psiquis tormentosa. Cuando suena la canción "Hand in my pocket", cada uno de los tres personajes comienza a danzar al compás de la música pero de una manera inusual para su estilo: al modo de la danza ritual de Potosí (según cómo la habían descripto previamente), cada cual compenetrado con su propio cuerpo, manifestando un caudal energético in crescendo y connotando aquella primitiva conexión de los orígenes del teatro con la danza, unión ritual con fines espirituales, como medio para la trascendencia de los seres partícipes. La ejecución por parte de las actrices y el actor de esta danza frenética e impulsiva, además de la descripción textual que se hace de ella, conlleva reminiscencias de aquella ritualesca y primigenia, remitiendo asimismo a los postulados del Teatro de la Crueldad planteados por Artaud en su intento de reescenificar y resignificar las fuerzas naturales y cósmicas, el espíritu total del hombre y no el hombre psicólogico y social, o, en sus propias palabras: "No podemos seguir prostituyendo la idea del teatro, que tiene un único valor: su relación atroz y mágica con la realidad y el peligro" (1971: 101). La presente escena finaliza cuando el hijo -cuya presencia perdura a pesar de su condición ausente o, dicho de otra manera, su ausencia irrevocable permanece como una resonancia presente en el interior de su madre-, espectador de la danza, es percibido por Virginia que automáticamente
En lo alto para siempre - Créditos de imagen: Gustavo Gorrini Gentileza: Prensa TNA - TC. 
comienza a llorar y le hace un gesto con la mano como deseando detenerlo, frenar sus perpetuas apariciones. Acto seguido, ella y Emilio se quedan un rato mirándose las manos, con los brazos en alto en una especie de puesta en suspenso del tiempo y del espacio. Podría pensarse también en cómo operan en este despliegue escénico los principios básicos de la preexpresividad planteados por Barba, los cuales sostienen la energía necesaria para la presencia en escena e implican una tensión entre fuerzas opuestas internas a cada actuante (en Fernández Peláez, 2014: 163).

En segundo lugar, en la escena final del texto espectacular, el personaje de Pablo ingresa con un vestuario que remite a aquellos de las danzas mencionadas, un colorido traje con una pollera repleta de cascabeles -en contraste con el vestuario neutro íntegramente de color negro que había llevado a lo largo de toda la puesta en escena-. Mientras la madre ha quedado sola, sentada en la reposera de la terraza con los ojos cerrados, su hijo vuelve a subir a la misma y salta, no una vez, sino una decena de veces más. En esta continua escenificación del salto abismal, como si ejecutara una especie de loop sempiterno de caída al vacío, el sonido de los cascabeles, al igual que las múltiples formas de saltar, va aumentando su velocidad, violencia y frenesí. Hasta que finalmente, luego de la última subida, salta hacia el centro del escenario para comenzar, ahora él, a llevar a cabo aquella danza ritual, primitiva, que le había conmovido en vida. Ésta no sólo representa el rito metafísico de los habitantes de Potosí, sino también la danza con la propia muerte -presente en numerosas culturas aborígenes-, operando, nuevamente, la alteridad en el cuerpo del actor: baila con la muerte Pablo, el personaje, mientras que al mismo tiempo es Pablo, el actor/performer/bailarín -tiene el mismo nombre que su personaje (otro posible componente de liminalidad) y sus destrezas físicas denotan un arduo entrenamiento corporal-, quien danza con la muerte misma del hecho teatral, la muerte de cada función, a través del cuerpo, soporte material primario de un fenómeno (el teatro) que nace para morir una hora después, cobra vida en dichos cuerpos, y en las miradas que los espectan, auto-consciente de su inminente fin, de su fugacidad. La presente danza, enérgetica, ruidosa y exaltada, actúa a modo de despedida polivalente: del acontecimiento teatral, de la vida del hijo, del recuerdo de su madre, del trabajo de las actrices y actores; las cuales son, a la vez, despedidas temporarias, ya que volverán a renacer a la función siguiente. De esta manera, tiene lugar "la bidimensionalidad propia del espectáculo teatral, que es siempre, al mismo tiempo, acontecimiento real y acontecimiento ficticio, presencia material y representación, performance autorreflexiva y referencia a otra cosa de por síficticia" (De Marinis, 1996: 179). Esta performance 3 también tiene su correlato en un poema que previamente lee Emilio, el cual habla de un hombre que baila en un traje en la montaña, y remite a un rito de danza con la muerte, subrayando una vez más dicha acción.

Por último, la atmósfera de la puesta en escena va mutando progresivamente: ésta es generada por los recursos lumínicos, entre los cuales se incluye una pantalla que funciona como fondo escenográfico de la puesta, y que evoca al cielo, que sería el paisaje abierto y exterior de una terraza. Al aproximarse la mencionada escena final, la composición lumínica se vuelve cada vez más nocturna: colores fríos, azules, tanto en los reflectores como en la pantalla (que, a lo largo de toda la puesta, se van modificando conjuntamente), en contraposición a las luces precedentes, de tonos mucho más vivos, naranjas, que remitían a un sol de mediodía. Así, el clima provocado refuerza al mismo significado: el final del día, de la función teatral, de la existencia individual. Asimismo, mediante diversos significantes, se genera una atmósfera acuática: la escena azulada, la casa inundada que se encuentra debajo de la terraza (a la que únicamente ingresa el hijo luego de su danza), los sonidos que aluden a mundos subacuáticos o celestiales, la metáfora filosófica acerca de los peces que narra Emilio, al mismo tiempo que Lidia rompe bolsa (situación que vuelve a provocar un tono absurdista debido a la reacción fría y desangelada de su madre que lo toma como una situación muy
3. Puede entenderse como el juego entre acción y actuación, que permite repensar el vínculo entre representación y presentación, o, como propone Prieto Stambaugh, la represent-acción, cuyo soporte fundamental -al igual que en toda performance- es el cuerpo y el énfasis en su dimensión material (2009: 13) 
natural y sin importancia, lo cual causa comicidad), hecho que también contrapone un nacimiento, una nueva luz, a tanta reiteración de ocaso. El presente conjunto de acciones conforma sutilmente una "textura que se asemeja al collage" o, podríamos decir, a una estructura de pensamientos oníricos que "parecen hablar del mundo de los sueños de sus creadores (...) y no al desarrollo de acontecimientos lógicamente estructurados" (Lehmann, 2013: 146). Esta idea también se explicita en palabras de Lidia, quien, al romper bolsa, dice que la cubrió una ola de sueño, por lo cual no sabe si lo que sucede es real o un sueño. Finalmente, Virginia queda sola nuevamente en la terraza, al igual que al comienzo de la puesta, en el mismo estado emocional afectado, vuelve a coquetear con el peligroso borde de la terraza, a mirar hacia el abismo donde su hijo perdió la vida, y a decidir que, ante la imposibilidad interna de saltar al vacío, únicamente puede permanecer en lo alto para siempre.

En conclusión, a pesar de presentar una tendencia logocéntrica y de posible drama moderno en su composición narrativa, En lo alto para siempre demuestra pertenecer también, en palabras de Lehmann, al nuevo paradigma del teatro posdramático propio de este siglo, en el que las nuevas estructuras y rasgos estilísticos se mezclan y fusionan con los tradicionales, provocando gran diversidad de posibilidades teatrales (2013: 40). El eje vertebrador de estas nuevas prácticas escénicas es el cuerpo: “el aura de la presencia corporal sigue siendo el punto del teatro en el cual ocurre repetidamente la desaparición, el fading, de toda significación en favor de una fascinación más allá del sentido, de una presencia actoral, del carisma o de la irradiación" (2013: 165). Así, en el caso de la puesta en escena objeto del presente análisis, es el cuerpo actuante precisamente el que se desintegra y "devertebra", al tiempo que sus repetitivos saltos al vacío constituyen un leitmotiv visual (y en la última escena, también sonoro) paradójicamente vertebrador de la totalidad de la puesta. Mientras que, simultáneamente, los continuos choques de la materialidad real en la escena "despiertan en el público emociones menos ilusorias, pues se trata de realidades en un tiempo presente compartido con el espectador" (Cornago, 2004: 600), un exceso de presencia material más real que la realidad que provoca tensión e incomodidad en el espectador obligado a presenciar el salto abismal que podría ser el suyo propio y que constituye, intrínsecamente, a cada hecho teatral.

Ficha técnica

En lo alto para siempre. Estrenada el 10 de mayo de 2018 en el Teatro Nacional Cervantes.

Con: Pablo "Kun" Castro, Delfina Colombo, María

Onetto, Marcelo Subiotto

Producción: Lucero Margulis

Asistencia de dirección: Marcelo Mendez

Asistencia de iluminación: Estefanía Piotrowski

Asistencia de escenografía y vestuario: Sofía Eliosoff

Colaboración artística: Ignacio Ceroi

Música: Guillermo Pesoa

Coreografía: Virginia Leanza

Iluminación: David Seldes

Escenografía y vestuario: Mariana Tirantte

Autoría y Dirección: Camila Fabbri y Eugenia Pérez Tomas 


\section{Q Bibliografía}

》 Artaud, A. (1971). El teatro y su doble. Buenos Aires: Sudamericana.

" Cornago, O. (2004). "El cuerpo invisible: teatro y tecnologías de la imagen”. En Arbor. Ciencia Pensamiento y Cultura, Vol. 177, No. 699/700, marzo-abril, Consejo Superior de Investigaciones Científicas. Consultado el 24 de junio de 2018 en http://arbor.revistas.csic.es/index.php/arbor/article/viewArticle/597

»De Marinis, M. (1996). Comprender el teatro. Lineamientos de una nueva teatrología. Buenos Aires: Galerna.

»Dubatti, J. (2016). Teatro-matriz, teatro liminal. Estudios de Filosofía del Teatro y Poética Comparada. Buenos Aires: Atuel.

» Fernández Peláez, J. (2014). “Auras de la presencia”. En telondefondo, Revista de Teoría y Crítica Teatral, nำ19, julio. Consultado el 25 de junio de 2018 en http:// www.telondefondo.org/numeros-anteriores/numero19/articulo/525/auras-dela-presencia.html

»Lehmann, H. (2013). Teatro posdramático. Murcia/México: CENDEAC/Paso de Gato.

»Prieto Stambaugh, A. (2009). "!Lucha libre! Actuaciones de teatralidad y performance". En Adame, D. (ed.), Actualidad de las artes escénicas. Perspectiva latinoamericana. (pp. 116 - 143). México: Universidad Veracruzana/Facultad de Teatro. Consultado el 26 de junio de 2018 en http://artesescenicas.uclm.es/index.php?sec $=$ texto\&id=250\&PHPSESSID $=$ azhwlexmmzvpjcee

» Trastoy, B. y Zayas de Lima, P. (2006). Lenguajes escénicos. Buenos Aires: Editorial Prometeo. 